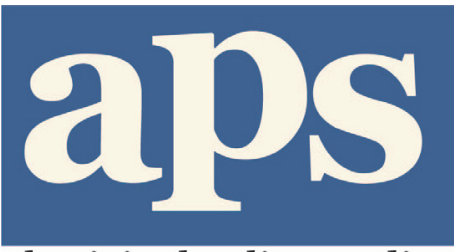

Commentary aboriginal policy studies

\title{
Transforming Relationships and Accessing Non- Insured Health Benefits Travel Funding to See Traditional Healers from Off-Reserve
}

\section{Michael Hankard \\ University of Sudbury}

aboriginal policy studies Vol. 1, no. 3, 2011, pp. 81-95

This article can be found at:

http://ejournals.library.ualberta.ca/index.php/aps/article/view/12184

ISSN: $1923-3299$

Article DOI: http://dx.doi.org/10.5663/aps.v1i3.12184

aboriginal policy studies is an online, peer-reviewed and multidisciplinary journal that publishes original, scholarly, and policy-relevant research on issues relevant to Métis, nonstatus Indians and urban Aboriginal people in Canada. For more information, please contact us at apsjournal@ualberta.ca or visit our website at www.ualberta.ca/nativestudies/ aps/ or http://ejournals.library.ualberta.ca/index.php/aps/. 


\section{Transforming Relationships and Accessing Non-Insured Health Benefits Travel Funding to See Traditional Healers from Off-Reserve}

Michael Hankard

University of Sudbury

Preface

This analysis took place within the context of research conducted in northern Ontario from 2009 to 2010 for my interdisciplinary dissertation research. Using interviews and textual analysis, my study explored the social organization of access to NIHB traditional healer travel funding for those living off-reserve. Each of the twenty-one participants in the study were assigned a pseudonym. At the end of this article, a partial list of all participant names is provided. Drawing from institutional ethnography (Smith 2006) and Indigenous knowledge approaches, I explored disjunctures between how off-reserve access to travel funding works officially in contrast to how it actually works from the perspectives of people who use it.

\section{Introduction}

According to the Traditional Healer Services Travel Policy of Health Canada's NonInsured Health Benefits program, travel funding is available to access traditional healers:

8.1 Medical transportation benefits, within the client's region/territory or residence, may be provided for clients to travel to see a traditional healer or, where economical, for a traditional healer to travel to the community (Health Canada 2005).

However, actually obtaining this funding from off-reserve is often easier said than done.

This article explores understandings of relationships from a First Nations and bureaucratic perspective to explicate disjunctures between how the Traditional Healer segment of Health Canada's Medical Transportation Policy Framework works officially and in practice. Through individual accounts and medicine circles, I illustrate changes that are taking place, and show how band members living off-reserve in northeastern Ontario have been affected while trying to access NIHB medical transportation funding. I also investigate commonalities that are useful for developing policy that benefits First Nations people living off-reserve.

\section{The Critical Nature of Relationships}

Relationships play a key role in obtaining travel funding to access traditional healers from off-reserve. However, bureaucracy is transforming traditional First Nations protocols for accessing healers. This transformation has changed how many people working onreserve and in First Nation organizations respond to inquiries from people living offreserve, and make access more bureaucratic and less First Nations-oriented. 


\section{Context: Accessing Traditional Healers Today and in the Past}

According to Métis Elder Michael Thrasher, accessing healers in the past ${ }^{1}$ was substantially different than today, ${ }^{2}$ and the change in how this was accomplished has been influenced by two primary factors. First is geography. The geographic area of this study is located north of the line separating First Nations who were primarily hunter-gatherers from those who were agriculturally-based. Hunter-gatherers had unique features, such as moving within particular territories in pursuit of game, demarcating hunting and fishing areas according to clan, and accessing healers differently than more sedentary First Nations. In addition, hunter-gatherers who tended to move freely in family-based units would typically meet in the spring and the fall to trade, exchange information, and for social reasons. At these times, information about medicines would be shared also (Michael Thrasher, personal communication).

The second major factor is the negative effects of colonialism (disease, war). Disease and war greatly reduced access to healers over time because a smaller First Nations population would, by definition, produce fewer healers. Even prior to the establishment of the Indian Act and residential schools, First Nations were forced from traditional lands and often separated from traditional plants and medicines. When the reserve system was established, people's movements were considerably restricted through regulations such as the pass system and restrictions on hunting and fishing rights. These regulations had a devastating affect on hunter-gatherers who had moved freely, hunted, fished, picked medicines, and accessed healers throughout northern Ontario for thousands of years.

Early within the traumatic period known as "contact" (roughly four hundred years ago), each community had their own healers and medicine people. Because of disease, war, colonialism, and the resulting destruction of most of the First Nations population, access to those traditional healers also decreased significantly. Elders have described how the availability of traditional healers decreased so much that First Nations went from having access to a local medicine person on a community level in the 1600s to accessing one on an area level (such as a regional area), to sub-provincial access, to provincial access, and finally to the point where we are today, in which healers are in such short supply that communities often bring them in from as far away as reserves in the US Midwest (Michael Thrasher, personal communication).

This shortage of traditional healers is compounded today by decreases in Indigenous knowledge within families relating to plants and medicines existing in northern Ontario. First Nations people in this area historically maintained a greater degree of self-sufficiency and did not access healers or doctors on an out-patient basis as is often done today. For most non-life threatening illnesses, families had a knowledge of plants, medicines, and first aid that was used for treating illnesses or injuries. Elders raised within the geographic area of this study, even those who were residential school attendees, can recall parents having a virtual storehouse of information about plants and medicines that were commonly picked, stored, and regularly used to maintain good health. Families also knew which medicines to take for promoting, as well as maintaining, good health. If a condition existed that a family could not deal with, there were often people within nearby communities who could be accessed for that knowledge. Traditional healers from outside communities tended only to 
be accessed for more serious conditions, such as cancer or locating lost loved ones who had failed to return from hunting, fishing, or the trap line.

Colonialism, in the guise of the widespread consumption of alcohol, has negatively affected this aspect of self-sufficiency. One visible outcome of this is lost understandings about plants and medicines, and how to use them to maintain good health. The loss of this knowledge, combined with the onset of Western medicine (also via colonialism) and accessing wellness through clinics, has changed how people understand and access health in general, and traditional healers in particular. In this way, because many people no longer have access to medicinal knowledge about plants for good health within their own families, healers are accessed for a wide range of illnesses and many other tasks. In this way, the work and the role of a traditional healer has expanded and increased in importance within First Nations communities.

Greater access to Western medicine, combined with less knowledge of plants and medicines, has led to more dependency on accessing institutional systems, instead of First Nations systems, for wellness. Accessing wellness in this way, such as becoming accustomed to seeking doctors in clinics on an outpatient basis, has also changed expectation levels of those accessing traditional healers. People are now more inclined to expect "instant" relief from a malady, such as one may obtain from taking a pill or an injection. Further, instead of being accessed only for the most serious of ailments, healers are now being accessed for solutions to a wide range of problems, including many of the same illnesses that Western doctors treat.

Changes in relationships are manifested through the ability to access travel funding for healers though institutional channels. Colonialism, it is important to note, causes these changes to take place within the context of fear. Institutional/bureaucratic relationships, which one is required to enter into to access travel funding, do not contain the same attributes as those historically existing within First Nations communities. This causes a great deal of stress and misunderstanding in communication. In many cases, the elements of healthy relationships (according to traditional learnings) have been altered by bureaucratic/ institutional ways of operating. This has led to a transformation in which respect, for example, has been replaced by a hierarchy of authority and specialized division of labor; time according to natural laws with efficiency and promotion driven by achievement; empathy with impersonal nature; and caring with written rules of conduct. These changes are only one of many that are rooted in colonial influence and have drastically changed the way that people now interact with each other.

\section{Relationships and Accessing Healers in the Past}

In the recent past, before and during the period when accessing healers began to be transformed, the relationship between a person and a healer would develop and evolve over a period of time, and required substantial commitment by the person seeking treatment as well as their family and community. It would often take an investment of time by a person just to prepare for accessing a healer. Initially, a person considering accessing a healer, if one was not available within their own community, would obtain information about one through personal, family, or community contacts. Tobacco and prints (offerings of 
coloured cloths) would then be personally given to the healer. This stage would involve travel by the person seeing treatment or, more usually, by someone acting on their behalf (a runner). If a healer accepted tobacco and prints, then the ill person could begin planning for travel to the healer. In addition, the runner may have been given instructions for the client on how to prepare for treatments they would be receiving.

When a runner returned from delivering tobacco and prints to the healer, preparations for travel began. The client and their family would begin preparing gifts for the healer and their helpers and materials necessary for travel. Organizing this material was a major commitment of time and energy. Depending upon the distance to the healer (and the patient's fitness for travel), the client and their family could spend substantial time getting to the healer's location. Travel was affected by geographic location, time of the year, and the ability of the person seeking treatment to sustain travel. Assuming that a client and their family were able to travel to a healer successfully, they would receive treatment for a period of time determined by the severity of the illness they sought treatment for. This could involve staying with the healer and their family during the duration of the winter, for example. In that case, it would be incumbent on the family of the client to provide food and other necessities for the healer and their family during their stay. When the client and family left to return to their own community, they would often leave gifts.

This initial visit to the healer was often the beginning of a longer relationship that evolved over a period of time. A patient would often return to the healer after their initial treatment was finished to ensure their health was stabilized. When a person returned to their community in good health, plans would sometimes be made to bring the healer into the community if a healer was not already available within that community.

If a community wanted to bring a healer in to work within it, a runner would offer tobacco and prints and make a request to that healer on behalf of the community. If tobacco and prints were accepted, the healer would confirm the time/date when they could come. The healer's preparation often involved time needed to determine the health requirements of the community prior to their visit. In addition, they had to organize and prepare remedies/ceremonies appropriate to the needs of the community. Further, because healers are accountable to elders, there would be consultations and permission gained from them prior to traveling to a community.

Healer compensation would often be provided in the form of something useful, like horses. If a healer and their helpers were being brought into a community for a week, for example, and they had to travel a substantial distance to get there, they would receive compensation commensurate with the ability of the community to provide it. This compensation could include horses, blankets, guns, tools, wild game, and other useful products. Money could also be provided. The time involved in planning, traveling, and working within the community could be several months.

Bringing a healer into a community required a great deal of commitment. Each person seeking treatment had to prepare prints, tobacco, and gifts, and take the time to prepare themselves mentally, physically, and spiritually. In addition to this work, there was the potential need for plants to be picked on the healer's instructions or for other work to do, such as fasting, in preparation of the healer's visit. 
Each step involved in accessing a healer developed within a relationship based on respect, time, empathy or feeling, and caring behavior. These characteristics were critical because they involved building trust between a client and healer. These four attributes were reciprocal-they were present in the relationship the healer had with the community and the one that the community had with the healer. The healer and the community accepted each other for who they were. The healer would not expect significant material objects from communities, and accepted people as they presented themselves. One writer in the Jesuit Relations, for example, describes a Huron healer who was physically deformed (he was a hunchback), but of note to the communities accessing him. In return for his work in one community, the only compensation the healer sought was a small pipe made from red pipestone and a pouch for his tobacco (Thwaites 1908, 33 and 101). The community also accepted healers for who they were: healers may have been two-spirited or nongender specific in orientation, as well. Medicine societies have regarded persons of these orientations as spiritually gifted and were known to adopt them into their societies.

Within the relationship of healer and patient, both parties understood the importance of time in developing and further healing treatments. The healer realized that their work was tied into time organized by natural laws, and that the ceremonies and plants used followed this continuum. Likewise, those seeking treatment had to invest significant amounts of time in developing and maintaining this relationship with the healer. People often did not see a healer just once. Empathy was an important attribute of healers, and had to be maintained and developed for healers to do their work. Similarly, people seeking healers on behalf of others were driven by feelings of empathy, either love of their family members needing treatment or for others, which also involved a significant investment of time. Finally, there had to be caring behavior that was evidenced by communities and families pulling together for the wellness of all concerned.

\section{How It Works Today}

Protocols for accessing healers still exist, but the establishment of bureaucratic protocols in order to obtain NIHB travel funding for accessing healers has been changed them. While First Nations stress individual free choice, bureaucracies stress control and regulation. The effect of bureaucracy has been evidenced through changes to historical First Nations ways of interacting and their transformation toward becoming more bureaucratic in nature. It would not be necessary to have inside contacts with workers to facilitate obtaining travel funding if First Nations principles were followed, because each person calling would be treated with respect, empathy and caring behavior in that case. Off-reserve band members identified non-cooperation by workers as the main obstacle to accessing funding and travel information, while front-line workers (to whom off-reserve band members turn for information) stated that non-cooperation by NIHB workers made accessing funding for applicants difficult. In both cases, front-line workers and off-reserve band members indicated that personal relationships were the only dependable means for navigating the institutional/bureaucratic barriers they encountered.

Participants living off-reserve stated that they were less able to obtain travel funding when they lacked relationships either with workers, staff, or others involved in organizing 
the pre-approval process. They also explained that living off-reserve and belonging to a different band interfered with their ability to obtain travel funding or information about travel funding. This is important to note because it reflects changes that have taken place in how First Nations relationships have been transformed into more impersonal and objectifying relations that characterize bureaucracies (Weber 1948, 254).

\section{The Effect of Bureaucratic Principles on Travel Funding from Off-Reserve}

Giizhik articulates the tension created by bureaucratic principles with regard to how inquiries from off-reserve are handled:

I think in First Nations - within the unit that I worked at, to do that additional work it was just a burden on the program workers themselves because they were stuck in that position for so long that they were not open to off-reserve members. I think there's a discrimination there-between on and off reserve; and they're not very helpful to the off reserve (interview, September 23, 2009).

She also indicated that providing program access to off-reserve members is not much of a priority:

There was no awareness from Chief and Council level either-none at all. There is no support for the off-reserve. They just said the funding was for on-reserve and that was all there is to it (interview, September 23, 2009).

M'Sheeken discovered first-hand the impersonal nature of bureaucracy when she tried to obtain information about obtaining NIHB travel funding from off-reserve. She explained:

I went to the First Nation here and asked if they would help and they said no-I needed to go to my community, and then I went to the (name omitted) First Nation and asked for help and they said, nope, they only help their own members and I was told that I would have to go to my own reserve. Then I went to (name omitted) First Nation, I called them and they said they couldn't help me because I wasn't living on the reserve (interview, September 12, 2009).

Megis, who also sought funding from his band initially, expressed his frustration by stating, "If I had the money up front, I would not need to do this. If I had the money up front, I would just go and see her." He began to question why he was being treated the way he was. "You wonder: Why am I going through this? This is my home rez. They are Indian. They're Nish, they should understand" (interview, September 19, 2009).

In contrast Ookwemin, who lives off-reserve but has an inside relationship with one of the workers, expressed a different experience. "It's easy to do. If you just come in here and get a prescription to see a healer and this and that and they give you a cheque" (interview, July 7, 2010).

\section{Worker Relations with Bureaucracy}

Workers within the system learn informal rules about how the pre-approval process really works through the establishment of personal relationships. Amik, who is a front line worker, described some of these rules as follows: 
I had a lot of success calling on a Friday because it seems like that's when they are going through their stuff. I don't know what they do-I guess they process everything for the whole week and I would never get anywhere if I called on a Monday or anything like that. I would always get a different worker every time. Each worker I would get would go back and pull up the paper-the request-and give me a totally different outlook on their findings-what they needed. So I had to learn right away to stick to one worker (interview, March 3,2010).

Amik also indicated the importance of getting "to know who the good workers are" and forming relationships with them. People often locate the "good workers" through recommendations made by other front-line workers they've maintained a relationship with. If they don't make these connections, bypassing this important step often means that one may "get a different worker every time" and experience arbitrary treatment by workers who are less than caring. These "rules" were learned from a more experienced worker with whom Amik has a long standing relationship. From a First Nations perspective, relationships also help one navigate varying responses from different NIHB regions.

M'kwa described how relationships affect access to travel funding and healers, saying that people learn about healers and the healer travel policy by "word of mouth." When healers are scheduled for certain areas, people usually find out this way:

There are certain families that access traditional healers-they find out a certain healer is in Sudbury, the Soo or even Toronto at (name of organization omitted) and want to go and see them. It's usually word of mouth-it goes really fast when a certain healer comes into town or a community (interview, February 18, 2010).

She also stated that her relationships with other workers, because no instructions were provided on how to interpret the policy, were instrumental in figuring out the Traditional Healer Services Travel Policy when it initially took effect in the 1990s.

Other workers also described how arbitrary treatment, based on the absence of relationships with NIHB workers, can differ by regional zones and affect travel funding. Ninatig, who was bewildered after trying to obtain travel funding for a family member to access a healer, questioned the assertions of the NIHB worker, saying, "Why are you refusing in this region, but in that region they can go?" She explained that speaking with different NIHB workers in different regional zone offices produced different answers to the same questions. While one NIHB zone office approved travel funding for a family with children, a different NIHB zone office only approved travel for the mother and not her children.

Several other participants (elders, clients) also stressed the need to develop and maintain relationships with the "good workers." They said that having contacts at NIHB instead of randomly speaking with workers determines success. In other words, making random calls to NIHB will likely obtain varied responses to queries. Workers doing so explained that they were forced to provide extensive explanations of case files and typically received conflicting responses about how they would be handled.

Personal relationships enable one to circumvent uncooperative front-line workers who, lack discretionary decision-making authority, tend to interpret forms and policies narrowly and not want to deal with situations that require interpretation. Asemaa stated 
that developing and maintaining a personal NIHB contact was the most important part of the pre-approval process (especially if you have a relative working there). Front-line NIHB workers are perceived by system users as the greatest hurdle,and are known for being the least cooperative. However, if one can sidestep them and speak to management, questions can often be resolved satisfactorily. At the management level, Asemaa observed more discretionary authority in decision-making and a willingness to reverse denials rendered by front-line workers.

\section{Nothing Beats a Properly Filled-Out Form}

In contrast to other workers identifying relationships as the key to accessing travel funding, Nodin states that a properly completed form is the most important aspect. She explained that the bureaucratic perspective of the Non-Insured Health Benefits office prioritizes properly completed forms above all else. In this way, the forms surpass any advantages gained through relationships, either with other workers or those working at Non-Insured Health Benefits. If the forms are in order and correctly filled out, she states, travel funding will be pre-approved regardless of the NIHB worker who processed it. The only catch to submitting properly completed forms, however, is finding someone to show you how to fill them out.

\section{Explicating Differences Through Medicine Circles}

Differences between First Nations and bureaucratic/institutional relations can be made visible from an Indigenous context using medicine circles. Examining the values of each reveals places of tension affecting obtaining travel funding and shows different priorities. The medicine circles in the two figures below highlight characteristics of bureaucratic principles and relevant First Nations beliefs to illustrate how they contrast and to find places of possible transformation. Bureaucratic/institutional principles (see Figure 1) generally include: (1) hierarchy of authority and a specialized division of labor; (2) a focus on efficiency and promotion driven by achievement; (3) an impersonal nature; and (4) the importance of texts and documents, as well as written rules of conduct (Weber 1948, 196240). In comparison, First Nations have historically organized relationships based on: (1) respect; (2) time; (3) empathy/feeling; and (4) caring behavior (Michael Thrasher, personal communication).

Bureaucratic operating principles, which organize the Medical Transportation Policy Framework, often replace historical First Nations ways of interacting. These are illustrated on the above medicine circle (see fig. 1) in categories related to standardization, impersonalization, rigid regulating policies, and inflexible rules. Generally, these qualities are one-dimensional and quantitative, reducing people to numerical objects. The bureaucratic way has consistency, but stifles innovation and free will. There are numerous rules and regulations that oversee the accounting process that were created by people who didn't have an understanding or concern for who First Nations people are and how we think. These organizations are also characterized by a top-down flow of authority. Orders given from higher authorities are expected to be followed without deviation or questioning. These protocols also separate and divide, are linear, and are exclusive instead of inclusive. 


\section{Bureaucracy/Institutional Relations}

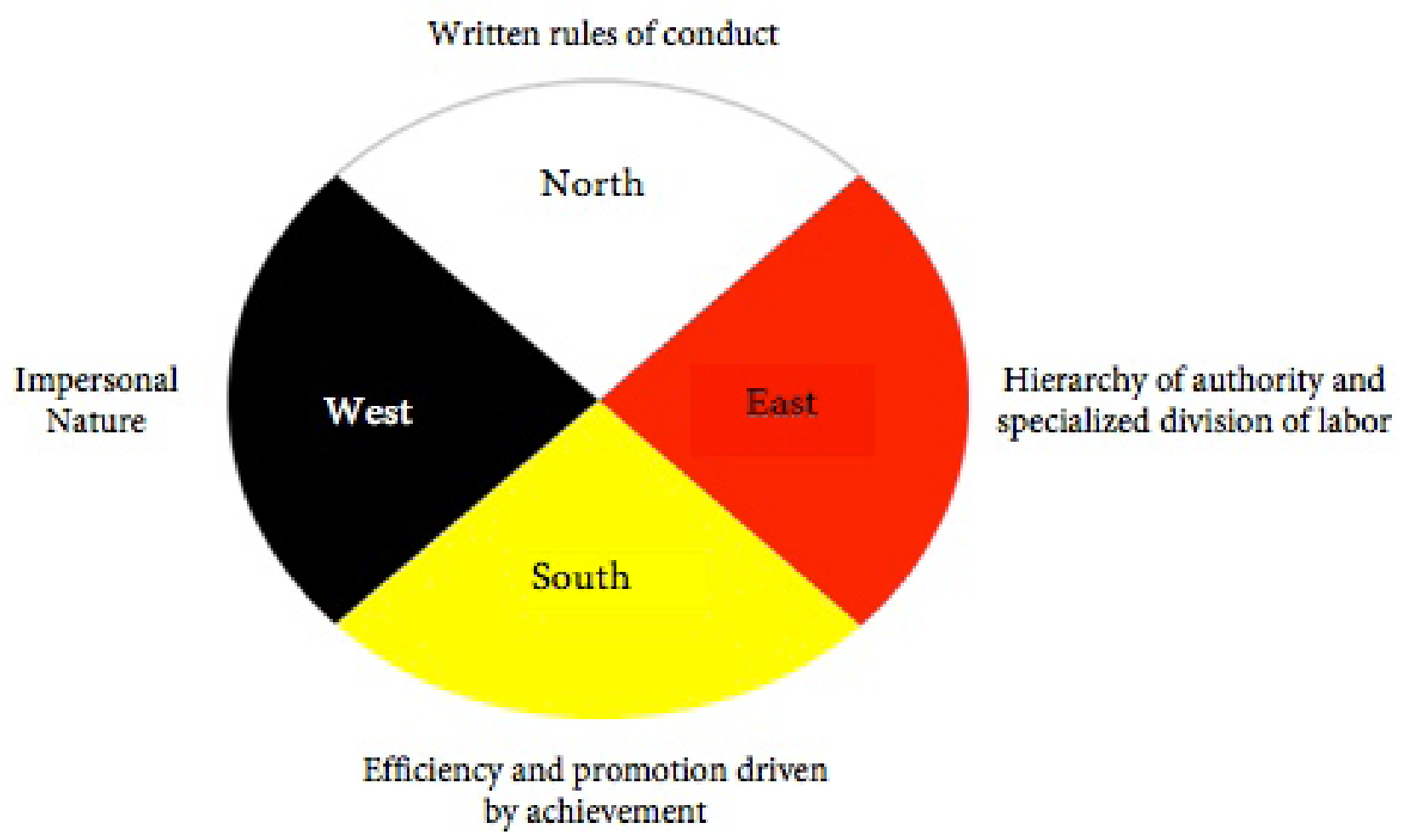

Fig. 1. Bureaucracy/Institutional Relations

Bureaucratic principles, such as formal rationality and minimized relationships, are preferred within a capitalist economy because they support efficiency, accountability, and the goals of a monetary economy. As Weber observed:

Money is the most abstract and "impersonal" element that exists in human life. The more the world of the modern capitalist economy follows its own immanent laws, the less accessible it is to any imaginable relationship with a religious ethic of brotherliness $(1948,331){ }^{4}$

Relying on money, which Weber notes as the "most abstract" and "impersonal element that exists in human life," to replace relations between people directly contrasts with First Nations understandings. The more this medium is used to structure relations, the more difficult it is to comprehend First Nations people through this bureaucratic lens.

In contrast to the goal-oriented approach of bureaucratic/institutional relations, First Nations learnings and philosophy provide the framework for relations between people. These emphasize Creation's interconnectedness, the holistic character of life, and the critical nature of balance. Because of the effects of colonialism, bureaucracy. which includes state and professional relations, has changed these ways in current practice. 


\section{Historical First Nations Relationships}

\section{Caring Behavior}

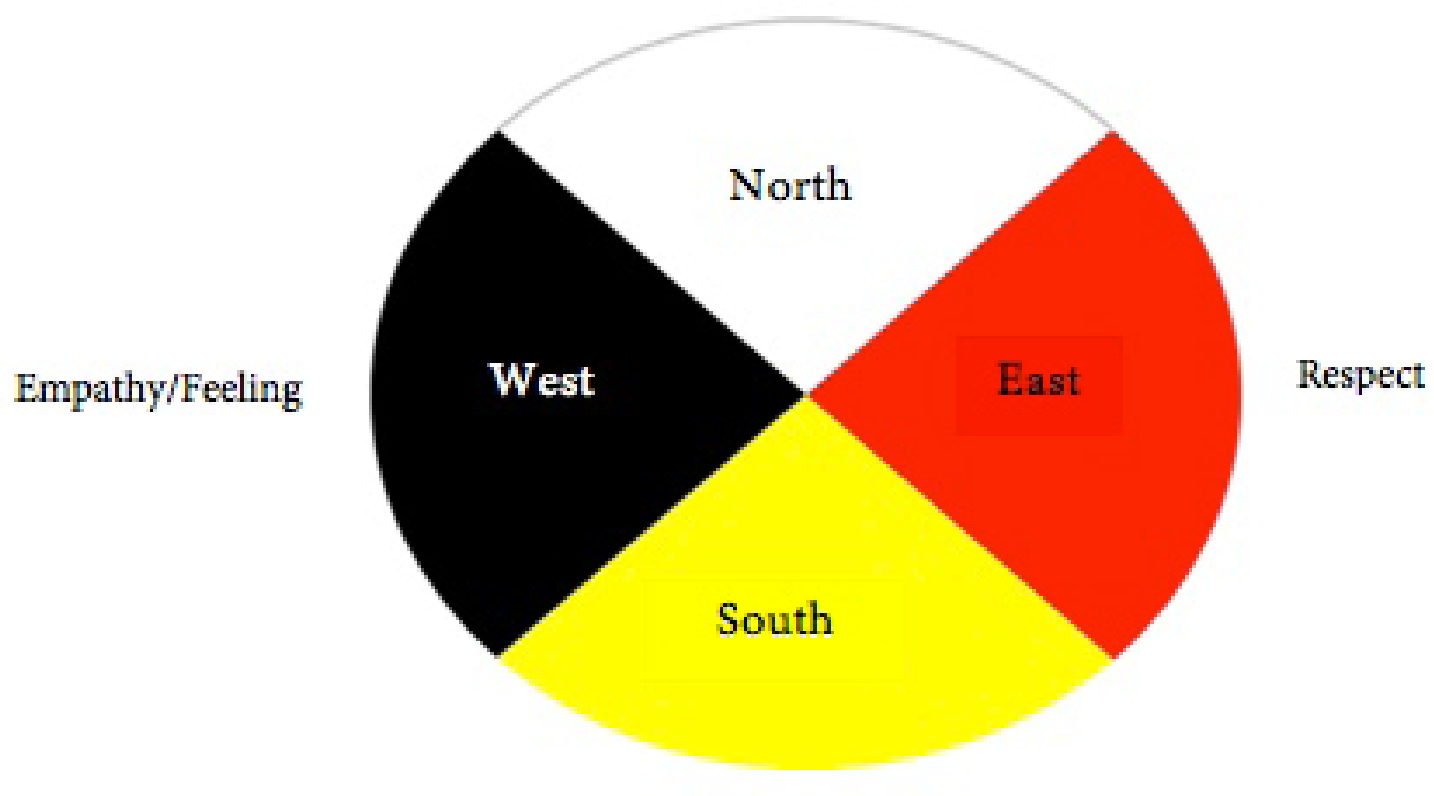

Time

Fig. 2. Historical First Nations Relationships

According to First Nations historical learnings, respect, time, empathy, and caring behavior are elements within healthy relationships (Michael Thrasher, personal communication). Respect is the need within relationships to "look twice" at someone. According to Elder Michael Thrasher, respect is broken down in two components: Re/ spect. This refers to seeing a person without judgment, accepting them, and allowing them to seek and pursue their talents, abilities, and lifestyle. In this understanding, all persons have gifts and abilities they are allowed to develop and grow into. People are not forced into roles (including gender roles) or positions they are ill-suited for.

Following respect is time. This conception of time differs from that used within bureaucratic or industrial relations based on productivity or clock time. Instead, this references time organized by the natural world (e.g., the changing of the seasons). Further, as indicated in earlier in the discussion on accessing healers in the past, time is required to form, build, and maintain relations. One must spend time with someone to get to know them and time is needed to maintain it, nurture it, and help relationships grow.

Next, empathy or feeling must be present in a relationship. This solidifies a connection between two people. If someone is experiencing a hardship, then empathy exists for what 
they are going through. The trials and tribulations of other people are not just ignored. Workers evidencing empathy for clients can place themselves in the shoes of the person on the other end of the phone. Even though they are restricted by rules and regulations, the willingness to explore ways to circumvent these rules is greater when this is present.

Finally, caring is required within a health relationship. Caring behavior is evidenced within a relationship by actually performing acts to help the person one is in a relationship with. There are many examples of this - they can be the "little things" (M'kwa, interview, 2010) one does that show how one cares for another person. For example, if a medical transportation clerk observes a person struggling to fill out the pre-approval forms, empathy for that person leads them to act and either offer advice or physically help them complete sections of the form they are having difficulty with.

\section{Differences Between First Nations and Bureaucratic Relationships}

Colonialism has drastically altered relationships between First Nations people. First Nations and bureaucratic ways of operating differ in several ways, with First Nations stressing the formation and maintenance of healthy relationships. In contrast, bureaucracy avoids them. Relationships remain the foundation of everything that First Nations people do, however; beyond the scope of human interaction, these relationships extend to the land, our past, present, and future, and ourselves, clans, families, and nations. Relationships are complex, continuous, growing, and adapting.

First Nation principles, based on our own spirituality, philosophy, and beliefs, also govern internal and external relations. First, as noted in the medicine circle discussion earlier, respect is a fundamental part of forming and maintaining a relationship according to First Nations understandings, but this cannot occur within a hierarchically organized bureaucracy using a formalized chain of command and specialized division of labour. Each person within a bureaucratically organized position is assigned a fixed position that may or may not be related to one's gifts or inherent tendencies. The bureaucratic organization is uninterested in "respecting" or accepting people for who they are-they only want the completion of a particular specialized function within the organization. People are transformed into objects and things. Further, within a chain of command, individual differences are not valued or accounted for. Instead, each person must stay within the confines of the position as it exists within the organizational structure or organizational relations.

When an organization lacks internal respect, its employees transfer this lack of respect outward to applicants, and this is what participants off-reserve encountered when seeking information about travel funding. The Western bureaucratic approach, as marked by impersonal relations, has filtered into our communities. It often replaces healthy relations between people living and working there, which in turn is manifested through bureaucratic management. In this way, many front-line workers alternate between following First Nations relationships and bureaucratic protocols that mandate being "impersonal" in client, band, and community relations. This often creates communication difficulties, and harms family and community relations. 
Bureaucracies seek greater efficiency by maximizing time allocation-the financial bottom line drives its goals. This has also transformed the historical First Nations understanding of time as it applies to relationships. Workers must process forms more quickly or risk losing their jobs, and case workers must manage larger and larger case loads. They also seek to promote workers based on productivity output, and punish those who produce less. This contrasts with historical relationship principles stating that time is needed for relations to properly take seed and grow. One cannot "just add water and stir" (Michael Thrasher, personal communication) to form a relationship. It must be nurtured, developed, and worked at to be maintained. Once a relationship has developed in its own time, however, it is long-standing, does not have an expiry date, and is not limited to the next fiscal quarter or influenced by financial bottom lines.

Bureaucracies prioritize impersonal relations with clients and coworkers. Workers are treated as objects and things and are taught to treat others in the same way. In this way, workers who would formerly empathize with others are forced to avoid forming emotional ties with each other and clients. In contrast, First Nations approaches stress connections among people. Feelings and empathy are important elements of relationships because this connects our spirit to our actions and strengthens family and community. Further, the interconnection between our mind, body, and spirit remains healthy when coherent. People do not operate impersonally within Creation, but are intertwined within it.

Finally, the governing of bureaucracies by legalistic rules and regulations shifts the emphasis from caring behavior to indifference. Texts, forms, and documents are used to regulate and standardize procedures across numerous work sites. Blindly following rules and regulations, without regard for individual circumstances, morality or ethics, has led to tragic consequences in the last century (as noted during the Nuremberg trials following World War II). So-called objectivity and neutrality does not allow deviations from policy or rules to include actions that First Nations would describe as caring behavior. As such, First Nations relationships stressing caring, evidenced by compassionate actions, are often replaced by bureaucratic protocols.

\section{Conclusion}

Bureaucratic obstacles to health policy, though formidable, are not insurmountable. Change is possible when one considers that both differences and commonalities exist. Focusing on those commonalities is one way to bring positive change. In both systems, applicants follow a series of protocols to access traditional healers through an established process. Second, both systems achieve results of some kind. The First Nations approach, which is rooted in free choice and free will, ultimately allows people to access healers on their own. The bureaucratic process, which is rooted in control and regulation, only permits access upon successful navigation of the pre-approval process and its maze of gatekeepers. Third, both systems are comprised of people who do the actual work needed to process forms, make calls, and put policy into motion.

Further, First Nations and people working for bureaucracies, especially front-line workers, have certain shared interests. First, they want to help people access traditional healers. Even though bureaucratic rules and regulations work against developing relations 
between workers and applicants, the goal of facilitating access remains important. Bureaucratic relations may operate according to neoliberal polices and fiscal constraints, while its workers want to help people have access. Many First Nations people and communities, although similarly constrained by neoliberal policies and differing religious beliefs, also generally want band members to have access to traditional healers if they so desire.

The second joint interest is caring about people's health and wellness, which includes empathy. Bureaucratic/institutional workers, including staff, officials, doctors, nurses, and others, care about and empathize with First Nations people. This is also the case within First Nation bands, organizations and friendship centres. Similarly, within First Nations families and communities, there is a great deal of caring and concern about wellness. At all levels of community, from chief and council, health staff, elders, and healers, caring and empathy is often evidenced by community healing initiatives and the willingness to spread nominal financial resources over as many programs and services as possible.

The third common goal is developing and maintaining a fair and equitable health access system. If this existed, the process for obtaining funding would be user friendly and applicants would not require specialized knowledge or inside contacts. Forms and procedures would be accessible and equally available to those living off-reserve. Receiving travel funding would not depend on personal contacts or relationships with those working in the band office or health centre.

Finally, an Elder interviewed in my study repeatedly emphasized that communication is one of the main problems in "Indian country" (Myeengun, interview, 2010). Therefore, building communication and establishing a dialogue are important initial steps toward making this policy accessible to those living off-reserve. This dialogue should be guided by First Nations understandings on relationships and the understanding that both parties are stakeholders with equal footing. When this happens, a policy may emerge reflecting the wants, needs, and desires of all First Nations people instead of budgets, accounting methods, and managerial practices.

\section{Endnotes}

1. The time period referred to here begins in the 1600s and lasts into the 1930s and 1940s.

2. For an interesting ethnographic study that includes a discussion of traditional healers in the Kenora, Ontario area in the 1930s, see Landes (1938).

3. This term is placed within quotation marks because contemporary historical sources assert contact beginning with the arrival of Christopher Columbus in 1492 or so; however, this conflicts with First Nations knowledge of contact, which is said to have been ongoing long before that. For a further discussion of this topics, see: Ronald Wright's Stolen Continents: Conquest and Resistance in the Americas (2003).

4. The gendered nature of this expression refers to Weber's perception, at that time, that work places were the exclusive domain of men. 


\section{Bibliography}

Gerth, H. H., and C.W. Mills, eds. 1948. From Max Weber: Essays in Sociology. Milton Park, UK: Routledge.

Health Canada. 2005. Non-Insured Health Benefits Program. Medical Transportation Policy Framework. Section 8. Traditional Healer Services Travel Policy.. http://www. hc-sc.gc.ca/fniah-spnia/pubs/nihb-ssna/_medtransp/2005_med-transp-framecadre/index-eng.php\#a8

-_-_- 2010. Client Identification. First Nations, Inuit and Aboriginal Health. http:// www.hc-sc.gc.ca/fniah-spnia/nihb-ssna/provide-fournir/client-beneficiaire-eng.php.

Kelly, Fred. 2008. "Confessions of a Born Again Pagan.” In From Truth to Reconciliation: Transforming the Legacy of Residential Schools, eds. Marlene Castellano Brant, Linda Archibald, and Mike DeGagne, 11-42. Ottawa: Aboriginal Healing Foundation.

Landes, Ruth. 1938. The Ojibway Woman. Lincoln: University of Nebraska Press.

Rankin, Janet, and Marie Campbell. 2006. Managing to Nurse: Inside Canada's Health Care Reform. Toronto: University of Toronto Press.

Royal Commission on Aboriginal Peoples (RCAP). 1996a. Report of the Royal Commission on Aboriginal Peoples. Volume 3: Gathering Strength Health and Healing. http://caid.ca/RRCAP3.3.pdf

_-__- 1996b. Report of the Royal Commission on First Nations Peoples. Volume 3: Gathering Strength, Section 3-Health and Healing, Part A. http://caid.ca/ RRCAP3.APP.A.pdf

———— - 1996c. Report of the Royal Commission on First Nations Peoples. Part Two: False Assumptions and a Failed Relationship, The Vision and Policies of Residential School Education, 1.1 The Vision. http://caid.ca/RRCAP1.10.pdf

Smith, Dorothy, E., ed. 2006. Institutional Ethnography as Practice. Toronto: Rowman and Littlefield.

Smith, Linda T. 1999. Decolonizing Methodologies: Research and Indigenous Peoples. New York: Zed Books.

Thwaites, Reuben Gold, ed. 1908. Hurons. Vol. 8 of The Jesuit Relations and Allied Documents. Travels and Explorations of the Jesuit Missionaries in New France, 1610-1791. Cleveland: The Borrows Brothers Company.

Tsing, Anna. 2004. "Unruly Edges: Mushrooms as Companion Species.” http:// drumstage.lib.umd.edu/bitstream/1903.TEST/11436/1/Unruly\%20Edges\%20\%20 Mushrooms\%20as\%20Companion\%20Species.htm.

Wilson, Shawn. 2008. Research is Ceremony: Indigenous Research Methods. Halifax and Winnipeg: Fernwood.

Wright, Ronald. 2003. Stolen Continents: Conquest and Resistance in the Americas. Toronto: Penguin Group. 


\section{Interviews}

2009 M'Sheeken (Turtle) is First Nations-kwe and lives off-reserve in northern Ontario. She accessed the Medical Transportation Policy to obtain travel funding to see a traditional healer and described her experiences (September 12, 2009).

2009 Megis (Shell) is First Nations from a reserve in northern Ontario. He lives offreserve and obtained travel funding to see a traditional healer from off-reserve. (September 19, 2009)

2010 M'kwa (Bear) is First Nations-kwe and has been worked in the field of First Nations health for over twenty years. (February 18, 2010)

2009 Mohneeze (Mary) is First Nations-kwe and has worked in First Nations health and advocacy organizations in Ontario for over twenty years. (September 16, 2009)

2009 Giizik (Cedar) is First Nations-kwe and has worked in First Nations health and advocacy organizations in Ontario for over twenty years. (September 23, 2009)

2009 Ookwemin (Black Cherry) is First Nations-kwe and lives off-reserve in northern Ontario. She accessed the Medical Transportation Policy to obtain travel funding to see a traditional healer and described her experiences. (July 7, 2010)

2009 Amik (Beaver) is First Nations-kwe and has worked in the field of traditional health and wellness for about fifteen years. (March 3, 2010)

2009 Ninatig (Maple) is First Nations-kwe and has worked as a healer's helper and front-line worker in the field of traditional health for over twenty years. (June 23, 2010)

2009 Asemaa (Tobacco) is First Nations-kwe been a front-line worker in First Nations health organizations for over twenty years. (April 7, 2010)

2009 Nodin (Wind) is First Nations-kwe and has worked in First Nations health programs for over twenty years. (April 12, 2010)

2009 Myeengun (Wolf) is a First Nations elder and healer who has been involved in First Nations health and wellness programs and services for over forty years. (January 21, 2010) 